\title{
HANDLING OF MICROFICHE
}

\author{
M. E. Gómez \\ European Southern Observatory \\ Library La Silla \\ Casilla 19001 - Santiago 19 \\ Chile
}

The microfiche received at the Library E.S.O. - La Silla, come from different sources: old journals out of print, articles in current journals which often include microfiche for long tables, catalogs and figures not suitable for normal printing, and larger catalogues of data (IUE, IRAS, etc.). These microfiche, coming either in journals or being a publication themselves, are ordered in the same way:

- Every microfiche is assigned a running number.

- Three cards are typed: the main one being by author, the second one by title of the article, and the third one by title of the journal. In addition, the running number that identifies the microfiche is typed on the upper right corner of each card. The total amount of microfiche that make up the article or publication is given at the lower center of each card.

- The cards are kept in a special catalogue cabinet labeled Microfiche., in strict alphabetical order, where the cards by author, title, and publication are mixed together.

- The microfiche themselves are kept in a plastic tray with fiche separators and index dividers with insertable label holders. These label holders are placed at an interval of every five fiche separators. The holders display the running numbers of the microfiche .

- In addition, every fiche separator carries on its front side an adhesive label which contains the same information as that found on the main card.

- Finally, in the cases where articles in printed form contain additional information on microfiche, the running number of the microfiche is entered at the beginning of the article. 